\title{
Prevention of fat-induced insulin resistance by salicylate
}

\author{
Jason K. Kim, ${ }^{1,2}$ Yoon-Jung Kim, ${ }^{2}$ Jonathan J. Fillmore, ${ }^{2}$ Yan Chen, ${ }^{1}$ Irene Moore, ${ }^{2}$ \\ Jongsoon Lee, ${ }^{3}$ Minsheng Yuan, ${ }^{3}$ Zhi Wei Li, ${ }^{4}$ Michael Karin, ${ }^{4}$ Pascale Perret, ${ }^{2}$ \\ Steven E. Shoelson, ${ }^{3}$ and Gerald I. Shulman ${ }^{1,2,5}$
}

\begin{abstract}
${ }^{1}$ Howard Hughes Medical Institute,
${ }^{2}$ Department of Internal Medicine, Yale University School of Medicine, New Haven, Connecticut, USA

3Joslin Diabetes Center and the Department of Medicine, Harvard Medical School, Boston, Massachusetts, USA

${ }^{4}$ Department of Pharmacology, University of California, San Diego, School of Medicine, La Jolla, California, USA

${ }^{5}$ Department of Cellular and Molecular Physiology, Yale University School of Medicine, New Haven, Connecticut, USA

Address correspondence to: Gerald I. Shulman, Howard Hughes Medical Institute, Yale University School of Medicine, Boyer Center for Molecular Medicine, 295 Congress Avenue, BCMM 254C, Box 9812, New Haven,

Connecticut 06536-8012, USA. Phone: (203) 737-1115; Fax: (203) 737-4059; E-mail: gerald.shulman@yale.edu.
\end{abstract}

Received for publication October 13, 2000, and accepted in revised form May 18, 2001.

Insulin resistance is a major factor in the pathogenesis of type 2 diabetes and may involve fat-induced activation of a serine kinase cascade involving IKK- $\beta$. To test this hypothesis, we first examined insulin action and signaling in awake rats during hyperinsulinemic-euglycemic clamps after a lipid infusion with or without pretreatment with salicylate, a known inhibitor of IKK- $\beta$. Whole-body glucose uptake and metabolism were estimated using $\left[3-{ }^{3} \mathrm{H}\right]$ glucose infusion, and glucose uptake in individual tissues was estimated using $\left[1-{ }^{14} \mathrm{C}\right] 2$-deoxyglucose injection during the clamp. Here we show that lipid infusion decreased insulin-stimulated glucose uptake and activation of IRS-1-associated PI 3-kinase in skeletal muscle but that salicylate pretreatment prevented these lipid-induced effects. To examine the mechanism of salicylate action, we studied the effects of lipid infusion on insulin action and signaling during the clamp in awake mice lacking IKK- $\beta$. Unlike the response in wild-type mice, IKK- $\beta$ knockout mice did not exhibit altered skeletal muscle insulin signaling and action following lipid infusion. In summary, high-dose salicylate and inactivation of IKK- $\beta$ prevent fat-induced insulin resistance in skeletal muscle by blocking fat-induced defects in insulin signaling and action and represent a potentially novel class of therapeutic agents for type 2 diabetes.

J. Clin. Invest. 108:437-446 (2001). DOI:10.1172/JCI200111559.

\section{Introduction}

Insulin resistance plays a primary role in the development of type 2 diabetes (1) and is a characteristic feature of other health disorders including obesity, dyslipidemias, hypertension, and cardiovascular disease (2). The mechanism by which insulin resistance occurs is unknown but may be related to alterations in fat metabolism (3). More than 30 years ago, Randle and colleagues (4) introduced the concept of substrate competition between glucose and fatty acid (i.e., glucose-fatty acid cycle) and postulated that fatty acids cause insulin resistance through an increase in the NADH/NAD and acetyl $\mathrm{CoA} / \mathrm{CoA}$ ratios and citrate, leading to the inhibition of pyruvate dehydrogenase (5) and phosphofructokinase activity (6). Subsequently, glucose 6-phosphate concentration increases, which leads to the inhibition of hexokinase activity and glucose uptake (7). Recent studies by our group have challenged this substrate competition mechanism and found that acute elevations in plasma fatty acids in humans result in decreased glucose transport activity, as reflected by decreased concentrations of intracellular glucose 6-phosphate (8) and glucose (9). Furthermore, we have demonstrated that an acute elevation of plasma fatty acids resulted in activation of protein kinase C- $\theta$ (PKC- $\theta$ ) (10), a serine kinase, and postulated that this leads to serine phosphorylation of insulin receptor substrate (IRS)-1, which reduces the ability of IRS-1 to activate phosphatidylinositol 3-kinase (PI 3-kinase), an important mediator of insulin signaling and action (11).

Almost 100 years ago, Williamson and colleagues (12) showed that high-dose salicylate treatment reduced the severity of glycosuria in diabetic patients, and in 1957, Reid and colleagues (13) further demonstrated that 10-14 days of aspirin treatment improved the results of oral glucose tolerance tests in diabetic patients. The mechanism by which salicylate may affect whole-body glucose homeostasis remained unknown until a recent finding by Yin and colleagues (14) that salicylate inhibits the activity of IкB kinase$\beta$ (IKK- $\beta$ ), a known serine kinase. In light of these findings, we hypothesized that salicylate might prevent fatinduced insulin resistance in skeletal muscle by inhibiting the activity of IKK- $\beta$ and subsequent serine phosphorylation of IRS- 1 by IKK- $\beta$ and decreased activation of IRS-1-associated PI 3-kinase. To test this 
hypothesis, we examined whether high-dose salicylate pretreatment would prevent fat-induced alterations in insulin activation of IRS-1-associated PI 3-kinase and skeletal muscle glucose uptake. In addition, we examined whether mice with inactivation of IKK- $\beta$ are protected from fat-induced alterations in skeletal muscle insulin signaling and action.

\section{Methods}

Study 1: effects of salicylate pretreatment on fat-induced insulin resistance in rats

Animals. Male Wistar rats weighing 275-300 g were obtained from Charles River Laboratories (Wilmington, Massachusetts, USA) and studied at least 5 days after arrival. Rats were housed under controlled temperature $\left(23^{\circ} \mathrm{C}\right)$ and lighting $(12$ hours of light, 0600-1800 hours; 12 hours of dark, $1800-0600$ hours) with free access to water and standard rat chow. All procedures were approved by the Yale University Animal Care and Use Committee.

Surgery and animal handling. At least 4 days before clamp experiments, rats were placed in individual cages with wire floors. The distal one third of each rat's tail was drawn through a hole placed low on the side of the cage and secured there with a rubber stopper. This arrangement was required to protect tail blood vessel catheters during experiments (15). Rats were free to move about and were allowed unrestricted access to food and water. Two tail vein infusion catheters were placed the day before the experiment, and one tail artery blood sampling catheter was placed 2-3 hours before the start of experiments (i.e., at 0700 hours). Catheters were placed percutaneously during local anesthesia with lidocaine while rats were restrained in a towel. Rats were returned to their cages after catheter placement with tails secured as described above and were free to move about during the experiments. Patency of the arterial catheter was maintained by a slow $(0.016 \mathrm{ml} / \mathrm{min})$ infusion of heparinized saline $(10 \mathrm{U} / \mathrm{ml})$.

Pretreatment of salicylate for 19 hours. Starting at 1200 hours on the day before the experiment, salicylate (for the salicylate and lipid-salicylate groups, $42 \mathrm{mg} / \mathrm{kg}$; Sigma Chemical Co., St. Louis, Missouri, USA) or saline (for the control and lipid groups, matching volume) was fed using oral gavage at 6-hour internals (i.e., at 1200, 1800 , and 2400 hours). The food was removed from the cage at 1700 hours for the overnight fasting of animals.

Infusion of lipid and/or salicylate for 5 hours. On the morning of experiment day (at 0700 hours), saline (control group, $n=7)$, salicylate $(7 \mathrm{mg} / \mathrm{kg} / \mathrm{h}$; salicylate group, $n=6)$, lipid ( $5 \mathrm{ml} / \mathrm{kg} / \mathrm{h}$, Liposyn II, triglyceride emulsion, 20\% wt/vol; Abbott Laboratories, North Chicago, Illinois, USA) and heparin ( $6 \mathrm{U} / \mathrm{h}$; lipid group, $n=7$ ), or lipid/heparin and salicylate (lipid-salicylate group, $n=7$ ) was infused for 5 hours (preinfusion period). A blood sample $(200 \mu \mathrm{l})$ was collected at the start of 5-hour lipid/salicylate infusion period for measurement of basal concentrations of glucose, insulin, free fatty acid (FFA), and salicylate. To estimate basal wholebody glucose turnover, HPLC-purified $\left[3-{ }^{3} \mathrm{H}\right]$ glucose (NEN Life Science Products Inc., Boston, Massachusetts, USA) was infused at a rate of $0.05 \mu \mathrm{Ci} / \mathrm{min}$ during the preinfusion period. Three blood samples (100 $\mu \mathrm{l})$ were collected during the last 30 minutes of this period for measurements of plasma glucose, insulin, FFA, salicylate, and $\left[{ }^{3} \mathrm{H}\right]$ glucose concentrations.

Hyperinsulinemic-englycemic clamp in awake rats. After the 5-hour lipid/salicylate infusion, a 70-minute hyperinsulinemic-euglycemic clamp was conducted with a prime-continuous infusion of human insulin (Humulin; Eli Lilly, Indianapolis, Indiana, USA) at a rate of $60 \mathrm{pmol} / \mathrm{kg} / \mathrm{min}$ to raise plasma insulin concentration to approximately 3,000 pM. In the lipid and lipid-salicylate groups, lipid and heparin were infused as in the preinfusion period. Blood samples were collected at 10-minute interval for the immediate measurement of plasma glucose concentration, and 20\% glucose was infused at variable rates to maintain plasma glucose at approximately $6 \mathrm{mM}$. Insulin-stimulated whole-body glucose flux were estimated using a prime-continuous infusion of $\left[3-{ }^{3} \mathrm{H}\right]$ glucose $(20 \mu \mathrm{Ci}$ bolus, $0.2 \mu \mathrm{Ci} / \mathrm{min}$ ) throughout the clamps. To estimate rates of insulin-stimulated glucose uptake and metabolism in vivo in individual tissues, 2-deoxy-D-[1$\left.{ }^{14} \mathrm{C}\right]$ glucose $\left(2-\left[{ }^{14} \mathrm{C}\right] \mathrm{DG}\right.$; NEN Life Science Products Inc.) was administered as a bolus $(20 \mu \mathrm{Ci})$ at $30 \mathrm{~min}-$ utes before the end of clamps. Blood samples $(60 \mu \mathrm{l})$ were taken at $42,44,47,50,55,60,65$, and 70 minutes after the start of clamps for the determination of plasma $\left[{ }^{3} \mathrm{H}\right]$ glucose, ${ }^{3} \mathrm{H}_{2} \mathrm{O}$, and $2-\left[{ }^{14} \mathrm{C}\right] D G$ concentrations. Given that 2-deoxyglucose is a glucose analogue that is phosphorylated but not metabolized, insulin-stimulated glucose uptake in individual tissues can be estimated by determining the tissue content of 2-deoxyglucose-6-phosphate. Additional blood samples $(100 \mu \mathrm{l})$ were obtained before the start and at the end of clamps for measurement of plasma insulin, FFA, and salicylate concentrations. All infusions were done using Razel syringe pumps (Razel Scientific Instrument, Stamford, Connecticut, USA). At the end of clamps, rats were anesthetized with sodium pentobarbital injection $(2 \mathrm{mg} / \mathrm{kg}$ body weight). Within 5 minutes, four muscles (soleus, gastrocnemius, tibialis anterior, and quadriceps) from both hindlimbs, epididymal white adipose tissue, intrascapular brown adipose tissue, and liver were taken. Each tissue, once exposed, was dissected out within 2 seconds, frozen immediately using liquid $\mathrm{N}_{2}$-cooled aluminum blocks, and stored at $-70^{\circ} \mathrm{C}$ for later analysis.

Study 2: effects of lipid infusion in mice with inactivation of IKK- $\beta$

Animals and surgery. To determine whether IKK- $\beta$ inactivation prevents fat-induced insulin resistance, the effects of lipid infusion on insulin action and signaling were examined in male whole-body heterozygous IKK- $\beta$ knockout (IKK- $\beta$ KO) and age-matched wild- 
type littermates (16). At least 4 days before hyperinsulinemic-euglycemic clamp experiments, mice were anesthetized with an intraperitoneal injection of ketamine $(100 \mathrm{mg} / \mathrm{kg}$ body weight $)$ and xylazine $(10 \mathrm{mg} / \mathrm{kg}$ body weight), and an indwelling catheter was inserted in the left internal jugular vein. The catheters were externalized through an incision in the skin flap behind the head, and the mice were returned to individual cages after the surgery (17). Mice fully recuperated from the surgery before in vivo experiments as reflected by their reaching preoperative weight. To conduct experiments in awake mice with minimal stress, a tail restraint method was used (17).

Hyperinsulinemic-englycemic clamp in awake mice. After an overnight fast, saline or lipid $(5 \mathrm{ml} / \mathrm{kg} / \mathrm{h}$, Liposyn II, triglyceride emulsion, $20 \% \mathrm{wt} / \mathrm{vol}$; Abbott Laboratories) and heparin $(6 \mathrm{U} / \mathrm{h}$ ) were infused for 5 hours (basal period) in the wild-type mice (control group, $n=4$; controllipid group, $n=3$ ) and IKK- $\beta$ KO mice (IKK- $\beta$ KO group, $n=4$; IKK- $\beta$ KO-lipid group, $n=5$ ). To estimate basal whole-body glucose turnover, $\left[3-{ }^{3} \mathrm{H}\right]$ glucose was infused at a rate of $0.05 \mu \mathrm{Ci} / \mathrm{min}$ during the basal period. A blood sample $(80 \mu \mathrm{l})$ was collected at the end of basal period for measurement of basal concentrations of glucose, insulin, FFA, and $\left[{ }^{3} \mathrm{H}\right]$ glucose. After the basal period, a 120-minute hyperinsulinemic-euglycemic clamp was conducted with a prime-continuous infusion of human insulin at a rate of $15 \mathrm{pmol} / \mathrm{kg} / \mathrm{min}$ to raise plasma insulin within a physiological range $(\sim 730 \mathrm{pM})$. Blood samples $(20 \mu \mathrm{l})$ were collected at 20 - to 30 -minute intervals for the immediate measurement of plasma glucose concentration, and $20 \%$ glucose was infused at variable rates to maintain plasma glucose at basal concentrations. Insulin-stimulated whole-body glucose flux were estimated using a prime-continuous infusion of $\left[3-{ }^{3} \mathrm{H}\right]$ glucose $(10 \mu \mathrm{Ci}$ bolus, $0.1 \mu \mathrm{Ci} / \mathrm{min}$; NEN Life Science Products Inc.) throughout the clamps. All infusions were done using microdialysis pumps (CMA/Microdialysis, North Chelmsford, Massachusetts, USA). To estimate insulin-stimulated glucose uptake and metabolism in individual tissues, 2- $\left[{ }^{14} \mathrm{C}\right] \mathrm{DG}$ (NEN Life Science Products Inc.) was administered as a bolus $(10 \mu \mathrm{Ci})$ at $75 \mathrm{~min}$ utes after the start of clamps. Blood samples $(20 \mu \mathrm{l})$ were taken at $80,85,90,100,110$, and 120 minutes after the start of clamps for the determination of plasma $\left[{ }^{3} \mathrm{H}\right]$ glucose, ${ }^{3} \mathrm{H}_{2} \mathrm{O}$, and $2-\left[{ }^{14} \mathrm{C}\right] \mathrm{DG}$ concentrations. At the end of clamps, mice were anesthetized, and tissues were taken for later analysis as described in Study 1.

Insulin signaling analysis. Insulin-stimulated tyrosine phosphorylation of IRS-1 and IRS-1-associated PI 3-kinase activity in skeletal muscle were measured by immunoprecipitating IRS-1 using antibody to IRS-1 (kindly provided by M. White, Joslin Diabetes Center, Boston, Massachusetts, USA) and assessing the incorporation of ${ }^{32} \mathrm{P}$ into PI to yield phosphatidylinositol-3monophosphate (17). Insulin-stimulated tyrosine phosphorylation of insulin receptor in skeletal muscle were measured using antibodies to phosphotyrosine (Upstate Biotechnology Inc., Lake Placid, New York, USA).
In vivo glucose flux analysis. Plasma glucose concentrations during clamps were analyzed using $10 \mu \mathrm{l}$ plasma by a glucose oxidase method on a Beckman glucose analyzer II (Beckman Instruments Inc., Fullerton, California, USA), and plasma insulin concentrations were measured by RIA using kits from Linco Research Inc. (St. Charles, Missouri, USA). Plasma FFA concentrations were determined using an acyl-CoA oxidase-based colorimetric kit (Wako Chemicals USA Inc., Richmond, Virginia, USA), and plasma salicylate concentration (Study 1) was determined using salicylate assay kit (Sigma Chemical Co.). For the determination of plasma $\left[3-{ }^{3} \mathrm{H}\right]$ glucose and $2-\left[{ }^{14} \mathrm{C}\right] \mathrm{DG}$ concentrations, plasma was deproteinized with $\mathrm{ZnSO}_{4}$ and $\mathrm{Ba}(\mathrm{OH})_{2}$, dried to remove ${ }^{3} \mathrm{H}_{2} \mathrm{O}$, resuspended in water, and counted in scintillation fluid (Ultima Gold; Packard Instrument Co., Meriden, Connecticut) on dual channels for separation of ${ }^{3} \mathrm{H}$ and ${ }^{14} \mathrm{C}$. The plasma concentration of ${ }^{3} \mathrm{H}_{2} \mathrm{O}$ was determined by the difference between ${ }^{3} \mathrm{H}$ counts without and with drying. For the determination of tissue 2-[ $\left[{ }^{14} \mathrm{C}\right] \mathrm{DG}-6$-phosphate (2-DG-6-P) content, tissue samples were homogenized, and the supernatants were subjected to an ion-exchange column to separate 2-DG-6-P from 2-DG, as described previously (15). The radioactivity of ${ }^{3} \mathrm{H}$ in muscle glycogen was determined by digesting muscle samples in $\mathrm{KOH}$ and precipitating glycogen with ethanol as described previously (15). Skeletal muscle and liver triglyceride concentrations (Study 1) were determined using triglyceride assay kit (Sigma Chemical Co.) and a method adapted from Storlien et al. (18).

Calculations. Rates of basal endogenous glucose production (EGP) and insulin-stimulated whole-body glucose uptake were determined as the ratio of the $\left[{ }^{3} \mathrm{H}\right]$ glucose infusion rate (disintegrations per minute $[\mathrm{dpm}] / \mathrm{min}$ ) to the specific activity of plasma glucose $(\mathrm{dpm} / \mu \mathrm{mol})$ during the final 30 minutes of basal and clamp periods, respectively. Endogenous glucose production during clamps was determined by subtracting the glucose infusion rate from the whole-body glucose uptake. Whole-body glycolysis was calculated from the rate of increase in plasma ${ }^{3} \mathrm{H}_{2} \mathrm{O}$ concentration, determined by linear regression of the measurements at 50 , $55,60,65$, and 70 minutes for Study 1 and at 80, 85, 90, 100,110 , and 120 minutes for the Study 2. Whole-body glycogen and lipid synthesis were estimated by subtracting whole-body glycolysis from whole-body glucose uptake, assuming that glycolysis and glycogen/lipid synthesis account for the majority of insulin-stimulated glucose uptake (19). Glucose uptake in individual tissues was calculated from plasma $2-\left[{ }^{14} \mathrm{C}\right] \mathrm{DG}$ profile, which was fitted with a double exponential curve using MLAB (Civilized Software, Bethesda, Maryland, USA) and tissue 2-DG-6-P content as described previously (15). Skeletal muscle glycogen synthesis was calculated from ${ }^{3} \mathrm{H}$ incorporation to muscle glycogen as described elsewhere (15). Skeletal muscle glycolysis was then estimated as the difference between muscle glucose uptake and muscle glycogen synthesis. 
Figure 1

Metabolic parameters and insulinstimulated whole-body and skeletal muscle (soleus) glucose uptake in awake control (black bars), salicylate (light gray bars), lipid (open bars), and lipid-salicylate (dark gray bars) rats. (a) Plasma salicylate concentrations during basal and hyperinsulinemic-euglycemic clamp. (b) Plasma FFA concentrations during basal and hyperinsulinemic-euglycemic clamp. (c) Insulin-stimulated whole-body glucose uptake in vivo. (d) Insulin-stimulated skeletal muscle glucose uptake in vivo. Values are means \pm SE for six to seven experiments. ${ }^{*} P<0.05$ versus control group.
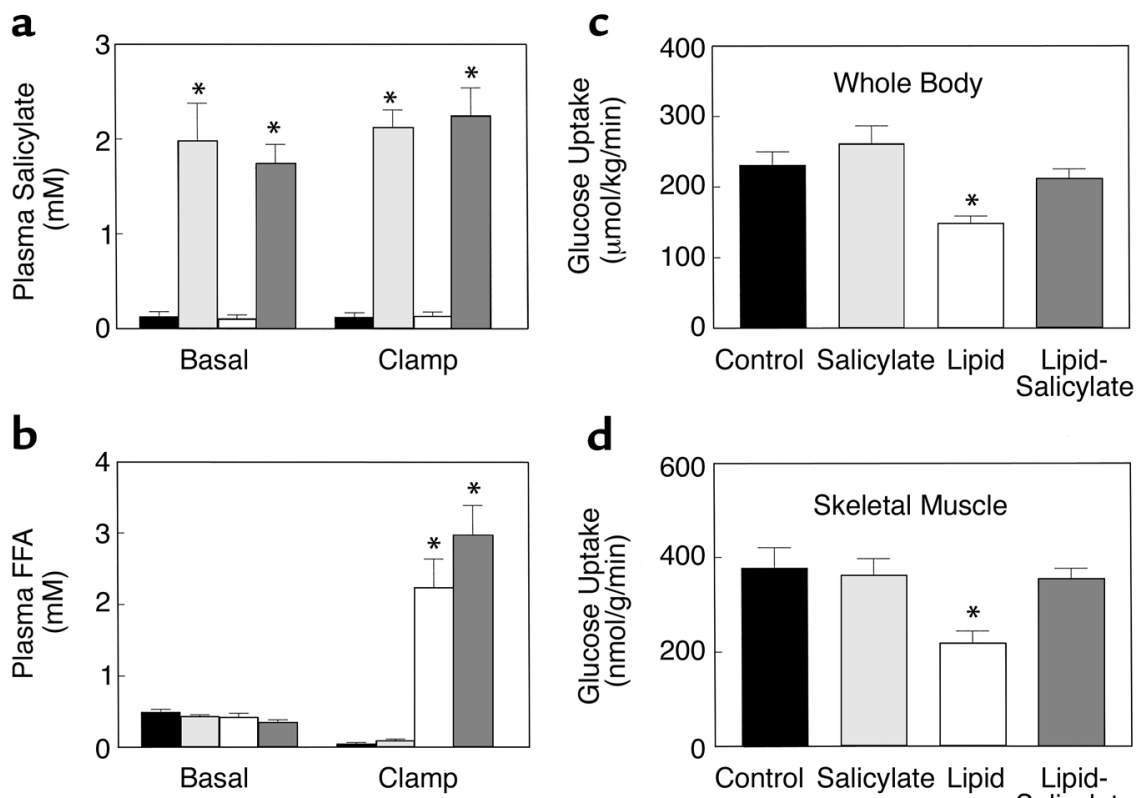

Statistical analysis. Data are expressed as means \pm SE. The significance of the difference in mean values among control, salicylate, lipid, and lipid-salicylate groups in Study 1 and among control, IKK- $\beta$ KO, control-lipid, and IKK- $\beta$ KO-lipid groups in Study 2 was evaluated using the Duncan's multiple range test.

\section{Results}

The effect of high-dose salicylate pretreatment on fatinduced insulin resistance was examined in awake rats. Plasma salicylate concentrations were raised to approximately $2 \mathrm{mM}$ after a 19-hour salicylate pretreatment and remained elevated during clamps in the salicylate and lipid-salicylate groups (Figure 1a). Plasma fatty acid concentrations were increased to approximately $2.5 \mathrm{mM}$ after a 5-hour lipid infusion and remained elevated during clamps in the lipid and lipid-salicylate groups (Figure 1b). In contrast, plasma fatty acid concentrations were suppressed by approximately $80 \%$ during clamps in the control and salicylate groups. A 19hour salicylate pretreatment or 5-hour lipid infusion did not alter plasma glucose and insulin concentrations (Table 1). During the clamps, plasma insulin concentrations were raised to approximately 3,000 pM, whereas plasma glucose was clamped at approximately $5.9 \mathrm{mM}$ in all groups (Table 1 ). The rate of glucose infusion needed to maintain euglycemia increased rapidly in the control and salicylate groups and reached a

\section{Figure 2}

Insulin-stimulated whole-body and skeletal muscle (soleus) glucose metabolic flux in awake control (black bars), salicylate (light gray bars), lipid (open bars), and lipid-salicylate (dark gray bars) rats. (a) Insulin-stimulated wholebody glycolysis in vivo. (b) Insulin-stimulated whole-body glycogen/lipid synthesis in vivo. (c) Insulin-stimulated skeletal muscle glycolysis in vivo. (d) Insulin-stimulated skeletal muscle glycogen synthesis in vivo. Values are means \pm SE for six to seven experiments. ${ }^{*} P<0.05$ versus control group.
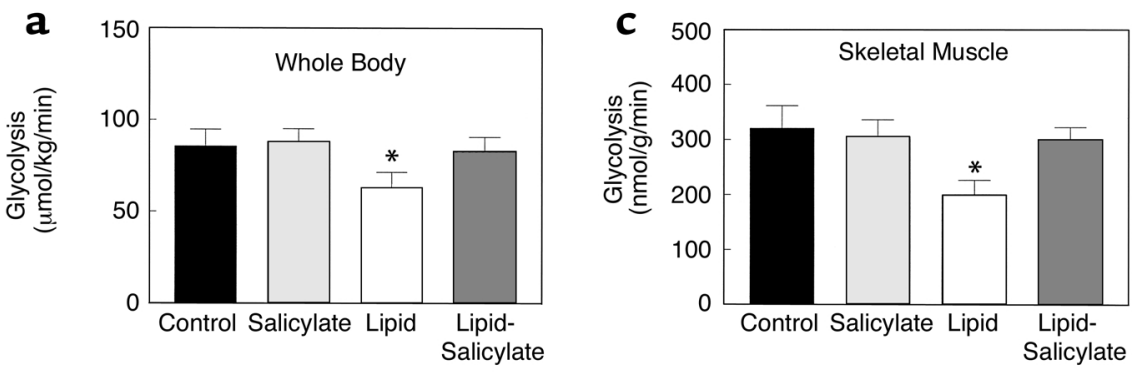

b

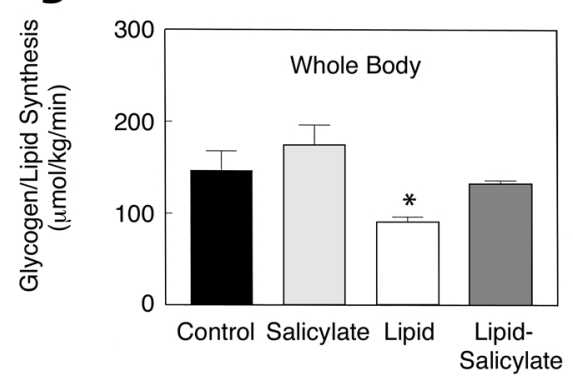

d

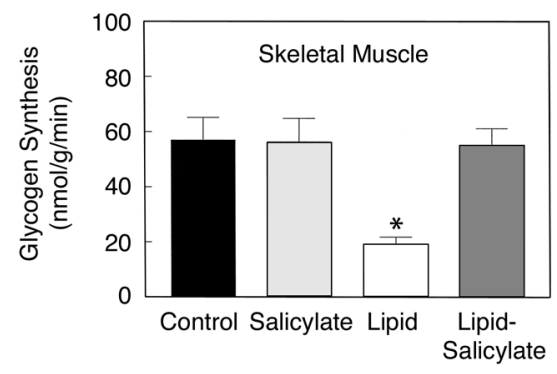


Table 1

Metabolic parameters during basal and hyperinsulinemic-euglycemic clamp periods and steady-state glucose infusion rate (GINF) ${ }^{A}$

\begin{tabular}{|c|c|c|c|c|c|c|c|c|c|c|c|}
\hline & & \multicolumn{5}{|c|}{ Basal period } & \multicolumn{5}{|c|}{ Clamp period } \\
\hline & $n$ & $\begin{array}{l}\text { Body } \\
\text { Weight } \\
\text { (g) }\end{array}$ & $\begin{array}{c}\text { Plasma } \\
\text { Glucose } \\
\text { (mM) }\end{array}$ & $\begin{array}{l}\text { Plasma } \\
\text { Insulin } \\
(\mathrm{pM})\end{array}$ & $\begin{array}{l}\text { Plasma } \\
\text { FFA } \\
(\mathrm{mM})\end{array}$ & $\begin{array}{l}\text { Plasma } \\
\text { Salicylate } \\
(\mathrm{mM})\end{array}$ & $\begin{array}{c}\text { Plasma } \\
\text { Glucose } \\
\text { (mM) }\end{array}$ & $\begin{array}{l}\text { Plasma } \\
\text { Insulin } \\
\text { (pM) }\end{array}$ & $\begin{array}{l}\text { Plasma } \\
\text { FFA } \\
(\mathrm{mM})\end{array}$ & $\begin{array}{l}\text { Plasma } \\
\text { Salicylate } \\
(\mathrm{mM})\end{array}$ & $\begin{array}{c}\text { GINF } \\
(\mu \mathrm{mol} / \\
\mathrm{kg} / \mathrm{min})\end{array}$ \\
\hline Control & 7 & $314 \pm 11$ & $5.7 \pm 0.2$ & $39 \pm 8$ & $0.49 \pm 0.04$ & $0.13 \pm 0.05$ & $6.0 \pm 0.2$ & $3,330 \pm 182$ & $0.05 \pm 0.02$ & $0.12 \pm 0.05$ & $231 \pm 19$ \\
\hline Salicylate & 6 & $322 \pm 11$ & $5.4 \pm 0.3$ & $41 \pm 6$ & $0.44 \pm 0.02$ & $1.98 \pm 0.40^{\mathrm{B}}$ & $5.5 \pm 0.2$ & $2,515 \pm 459$ & $0.09 \pm 0.02$ & $2.11 \pm 0.20^{\mathrm{B}}$ & $262 \pm 25$ \\
\hline Lipid & 7 & $301 \pm 14$ & $6.1 \pm 0.3$ & $63 \pm 18$ & $0.42 \pm 0.06$ & $0.11 \pm 0.04$ & $5.8 \pm 0.2$ & $3,172 \pm 313$ & $2.24 \pm 0.40^{\mathrm{B}}$ & $0.13 \pm 0.05$ & $148 \pm 11^{\mathrm{B}}$ \\
\hline Lipid-salicylate & 7 & $310 \pm 9$ & $6.0 \pm 0.3$ & $51 \pm 14$ & $0.35 \pm 0.03$ & $1.74 \pm 0.20^{\mathrm{B}}$ & $6.2 \pm 0.1$ & $2,832 \pm 319$ & $2.97 \pm 0.41^{\mathrm{B}}$ & $2.24 \pm 0.30^{\mathrm{B}}$ & $213 \pm 13$ \\
\hline
\end{tabular}

${ }^{A}$ Obtained from averaged rates of $40-70$ minutes of clamps in the control, salicylate, lipid, and lipid-salicylate groups; ${ }^{B} P<0.001$ vs. control group by the Duncan's multiple range test.

steady state within 30 minutes. In contrast, the glucose infusion rate required to maintain euglycemia in the lipid group was markedly reduced (Table 1), indicating that lipid infusion caused insulin resistance in these animals. Salicylate pretreatment prevented the lipidinduced decrease in steady-state glucose infusion rate. Insulin-stimulated whole-body glucose uptake was decreased by $37 \%$ with the lipid infusion (Figure 1c). Salicylate pretreatment prevented decreases in insulinstimulated whole-body glucose uptake caused by lipid infusion. Decreases in insulin-stimulated whole-body glucose uptake were due to a $41 \%$ decrease in insulinstimulated glucose uptake in skeletal muscle (soleus) with lipid infusion (Figure 1d). Salicylate pretreatment also prevented the lipid-induced decrease in insulinstimulated skeletal muscle glucose uptake. Furthermore, insulin-stimulated whole-body glycolysis and glycogen/lipid synthesis were significantly decreased by $27 \%$ and $43 \%$, respectively, with the lipid infusion (Figure 2 , a and b). Salicylate pretreatment prevented these decreases in insulin-stimulated whole-body glucose metabolic flux caused by lipid infusion. Similar to the decreases in insulin-stimulated whole-body glucose metabolic flux with lipid infusion, insulin-stimulated skeletal muscle glycolysis was decreased by $36 \%$ with lipid infusion (Figure 2c), but the most profound change was a $66 \%$ decrease in insulin-stimulated skeletal muscle glycogen synthesis with lipid infusion (Figure $2 \mathrm{~d}$ ). Salicylate pretreatment also prevented the lipid-induced decreases in insulin-stimulated skeletal muscle glucose metabolism.

Decreases in insulin-stimulated glucose uptake and metabolism in skeletal muscle were associated with a $59 \%$ decrease in insulin-stimulated tyrosine phosphorylation of IRS-1 in skeletal muscle (gastrocnemius) with lipid infusion (Figure 3b). Also, insulin-stimulated IRS-1-associated PI 3-kinase activity in skeletal muscle was decreased by $38 \%$ with lipid infusion (Figure $3 c$ ). These findings suggest that skeletal muscle insulin resistance with lipid infusion may be secondary to the observed defects in skeletal muscle insulin signaling. Lipid-induced decreases in both insulinstimulated tyrosine phosphorylation of IRS-1 and IRS-1-associated PI 3-kinase activity in skeletal muscle were prevented with salicylate pretreatment. In contrast, insulin-stimulated tyrosine phosphorylation of insulin receptor was not altered with lipid infusion or salicylate pretreatment (Figure 3a). These findings further suggest that lipid-induced defect and the effect of salicylate on skeletal muscle insulin signaling lie downstream to the insulin receptor and likely reside at the level of insulin receptor substrate.

In contrast to the defects in skeletal muscle insulin signaling and action with lipid infusion, basal EGP and insulin's ability to suppress basal EGP were not altered

a

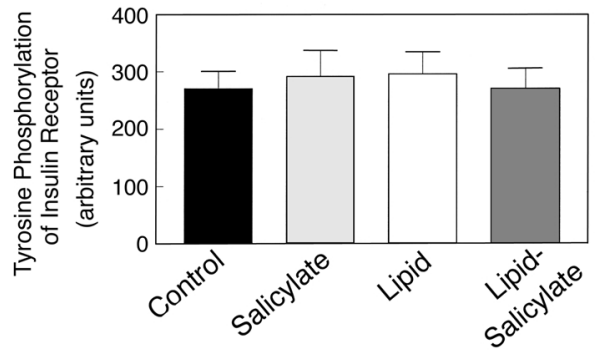

b

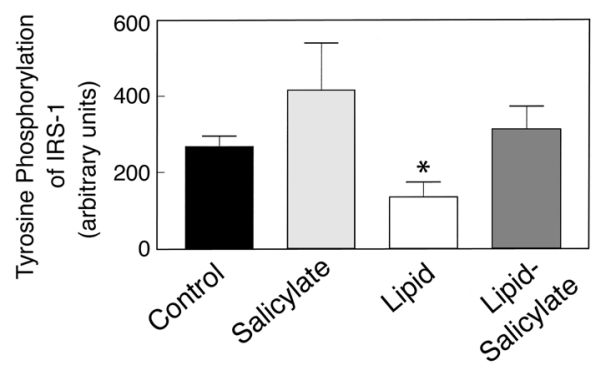

C

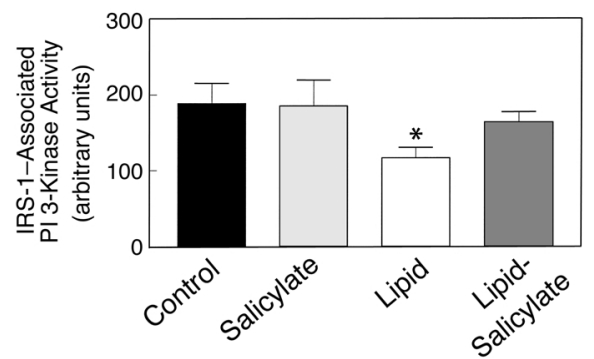

Figure 3

Insulin signaling in skeletal muscle (gastrocnemius) of the control (black bars), salicylate (light gray bars), lipid (open bars), and lipidsalicylate (dark gray bars) rats. (a) Insulin-stimulated tyrosine phosphorylation of insulin receptor. (b) Insulin-stimulated tyrosine phosphorylation of IRS-1. (c) Insulin-stimulated IRS-1-associated PI 3-kinase activity. Values are means \pm SE for six to seven experiments. ${ }^{*} P<0.05$ versus control group. 
a

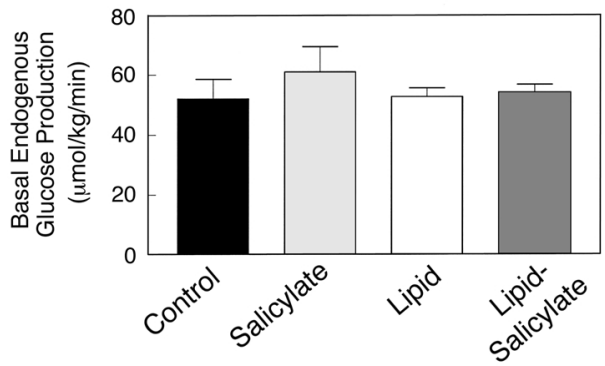

b

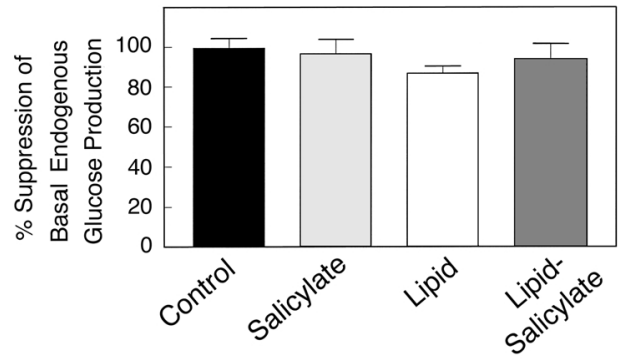

c

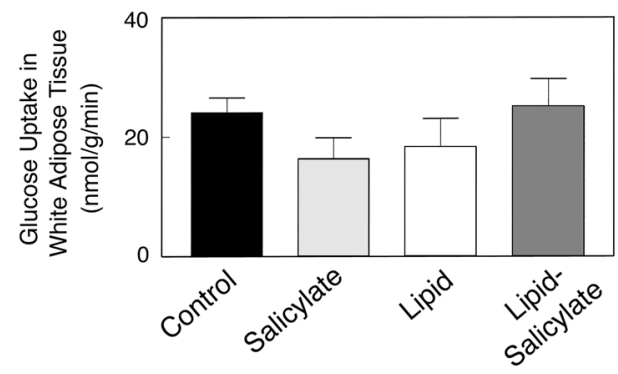

Figure 4

Insulin action in liver and epididymal white adipose tissue in the control (black bars), salicylate (light gray bars), lipid (open bars), and lipid-salicylate rats (dark gray bars). (a) Basal rates of endogenous glucose production. (b) Percent suppression of basal endogenous glucose production during insulin-stimulated state. (c) Insulin-stimulated glucose uptake in epididymal white adipose tissue. Values are means $\pm \mathrm{SE}$ for six to seven experiments.

with lipid infusion or salicylate pretreatment (Figure 4, $a$ and b). Moreover, insulin-stimulated glucose uptake in epididymal white adipose tissue was not altered with lipid infusion or salicylate pretreatment (Figure 4c). These findings indicate that increased plasma fatty acid concentrations caused a selective decrease in insulin responsiveness in skeletal muscle, which may be attributed to decreases in skeletal muscle insulin signaling and action, and that these defects were prevented with salicylate pretreatment.

To further determine the mechanism of salicylate action, we examined whether mice with inactivation of IKK- $\beta$ are protected from fat-induced insulin resistance in skeletal muscle. A 5-hour lipid infusion increased plasma fatty acid concentrations threefold during the basal period and more than 15 -fold during the clamps compared with the control group (Table 2 and Figure 5a). During the clamps, plasma insulin concentrations were raised to approximately $730 \mathrm{pM}$, whereas plasma glucose was clamped at approximately $6.5 \mathrm{mM}$ in all groups (Table 2). Lipid infusion markedly decreased the glucose infusion rate required to maintain euglycemia in the control mice, indicating that lipid infusion caused insulin resistance in these mice. In contrast, lipid infusion did not alter steady-state glucose infusion rate in the IKK- $\beta$ KO mice compared with the control and IKK- $\beta$ KO mice without lipid infusion (Table 2). Basal EGP and insulin's ability to suppress basal EGP were unaltered with lipid infusion in the control and IKK- $\beta$ KO mice (Figure $5 b$ ).

Insulin-stimulated whole-body glucose uptake was decreased by $28 \%$ with lipid infusion, and this change was due to a $56 \%$ decrease in insulin-stimulated skeletal muscle glucose uptake with lipid infusion in the control mice (Figure 5, c and d). In contrast, lipid infusion did not alter insulin-stimulated whole-body and skeletal muscle glucose uptake in the IKK- $\beta$ KO mice compared with the control mice (Figure 5, $\mathrm{c}$ and d). Furthermore, insulin-stimulated whole-body glycolysis was unaltered, whereas whole-body glycogen/lipid synthesis was significantly decreased by $62 \%$ with lipid infusion in the control mice (Figure 6, a and b). Insulin-stimulated skeletal muscle glycolysis and glycogen synthesis were significantly decreased by $56 \%$ and $58 \%$, respectively, with lipid infusion in the control mice (Figure 6, $c$ and d). These defects in insulinstimulated whole-body and skeletal muscle glucose metabolism with lipid infusion were prevented in the IKK- $\beta$ KO mice (Figure 6).

Decreases in insulin-stimulated glucose uptake and metabolism in skeletal muscle of control mice were associated with a $43 \%$ decrease in insulin-stimulated

Table 2

Metabolic parameters during basal and hyperinsulinemic-euglycemic clamp periods in the control, IKK- $\beta$ KO, lipid-infused control, and lipidinfused IKK- $\beta$ KO mice at $\sim 20$ weeks of age

\begin{tabular}{|c|c|c|c|c|c|c|c|c|c|}
\hline & \multirow[b]{2}{*}{$n$} & \multirow[b]{2}{*}{$\begin{array}{l}\text { Body } \\
\text { Weight } \\
\text { (g) }\end{array}$} & \multicolumn{3}{|c|}{ Basal period } & \multicolumn{4}{|c|}{ Clamp period } \\
\hline & & & $\begin{array}{c}\text { Plasma } \\
\text { Glucose } \\
\text { (mM) }\end{array}$ & $\begin{array}{c}\text { Plasma } \\
\text { Insulin } \\
\text { (pM) }\end{array}$ & $\begin{array}{l}\text { Plasma } \\
\text { FFA } \\
(\mathrm{mM})\end{array}$ & $\begin{array}{c}\text { Plasma } \\
\text { Glucose } \\
(\mathrm{mM})\end{array}$ & $\begin{array}{c}\text { Plasma } \\
\text { Insulin } \\
\text { (pM) }\end{array}$ & $\begin{array}{l}\text { Plasma } \\
\text { FFA } \\
(\mathrm{mM})\end{array}$ & $\begin{array}{c}\text { GINF } \\
(\mu \mathrm{mol} / \mathrm{kg} / \mathrm{min})\end{array}$ \\
\hline Control & 4 & $28 \pm 2$ & $6.8 \pm 0.6$ & $60 \pm 14$ & $0.57 \pm 0.06$ & $7.0 \pm 0.2$ & $678 \pm 97$ & $0.15 \pm 0.03$ & $231 \pm 20$ \\
\hline IKK- $\beta$ KO & 4 & $25 \pm 2$ & $7.9 \pm 0.4$ & $52 \pm 12$ & $0.49 \pm 0.15$ & $6.5 \pm 1.0$ & $804 \pm 130$ & $0.18 \pm 0.05$ & $230 \pm 17$ \\
\hline Control-Lipid & 3 & $31 \pm 2$ & $7.9 \pm 1.2$ & $44 \pm 23$ & $1.68 \pm 0.21^{\mathrm{A}}$ & $6.1 \pm 0.6$ & $764 \pm 120$ & $1.84 \pm 0.43$ & $3^{A} \quad 143 \pm 17^{A}$ \\
\hline IKK- $\beta$ KO-Lipid & 5 & $28 \pm 3$ & $7.6 \pm 0.5$ & $40 \pm 5$ & $1.55 \pm 0.14^{\mathrm{A}}$ & $6.5 \pm 1.0$ & $770 \pm 80$ & $1.62 \pm 0.41$ & $1^{\text {A }} \quad 240 \pm 36$ \\
\hline
\end{tabular}

AP $<0.05$ versus control group by the Duncan's multiple range test. 
a

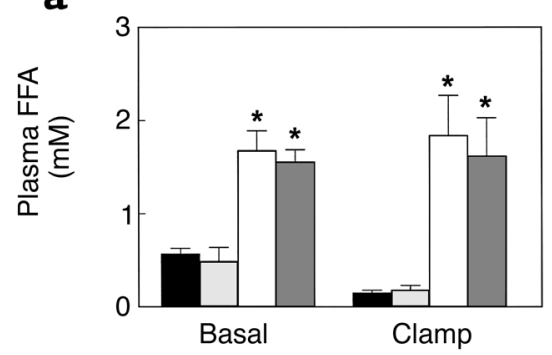

b

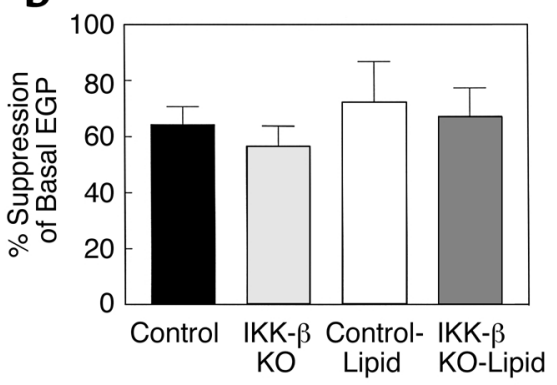

\section{C}

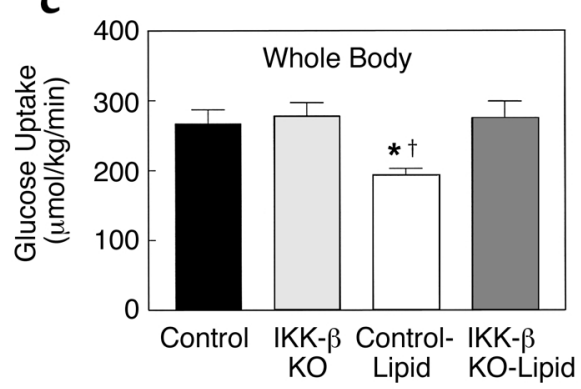

d

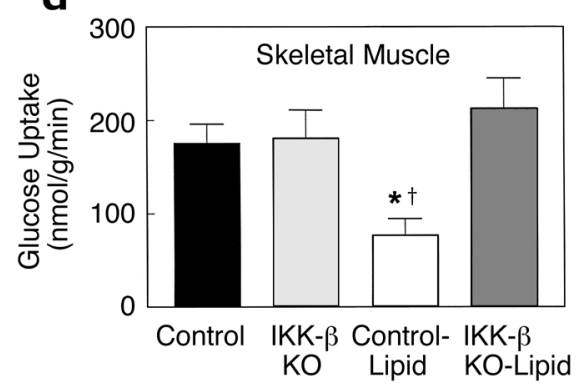

\section{Figure 5}

Metabolic parameters and insulinstimulated whole-body and skeletal muscle (gastrocnemius) glucose uptake in awake control (black bars), IKK- $\beta$ KO (light gray bars), controllipid (open bars), and IKK- $\beta$ KO-lipid (dark gray bars) mice. (a) Plasma FFA concentrations during basal and hyperinsulinemic-euglycemic clamp. (b) Insulin-stimulated percent suppression of basal EGP. (c) Insulin-stimulated whole-body glucose uptake in vivo. (d) Insulin-stimulated skeletal muscle glucose uptake in vivo. Values are means $\pm \mathrm{SE}$ for three to five experiments. ${ }^{*} P<0.05$ versus control group; $\dagger P<0.05$ versus IKK- $\beta$ KO-lipid group. tyrosine phosphorylation of IRS-1 in skeletal muscle (gastrocnemius) with lipid infusion (Figure 7a). Also, insulin-stimulated IRS-1-associated PI 3-kinase activity in skeletal muscle was decreased by $37 \%$ with lipid infusion in the control mice (Figure 7b). Lipid-induced decreases in both insulin-stimulated tyrosine phosphorylation of IRS-1 and IRS-1-associated PI 3-kinase activity in skeletal muscle were prevented in the IKK- $\beta$ $\mathrm{KO}$ mice (Figure 7 , $\mathrm{a}$ and $\mathrm{b}$ ). These findings suggest that the lipid-induced decreases in insulin-stimulated skeletal muscle glucose uptake in the control mice were secondary to the defects in muscle insulin signaling and that the IKK- $\beta$ inactivation prevented these lipidinduced defects in muscle insulin signaling and action.
In addition to lipid-induced defects in skeletal muscle insulin signaling and action, insulin-stimulated glucose uptake in brown adipose tissue was decreased by $54 \%$ with lipid infusion in the control mice, and this lipid-induced defect was also prevented in the IKK- $\beta$ KO mice (Figure 7c). Interestingly, insulinstimulated glucose uptake in epididymal white adipose tissue showed a tendency to increase with lipid infusion in the IKK- $\beta$ KO mice but did not reach statistical significance (Figure 7d).

\section{Discussion}

In this study, we found that a 5-hour lipid infusion decreased insulin-stimulated glucose uptake and
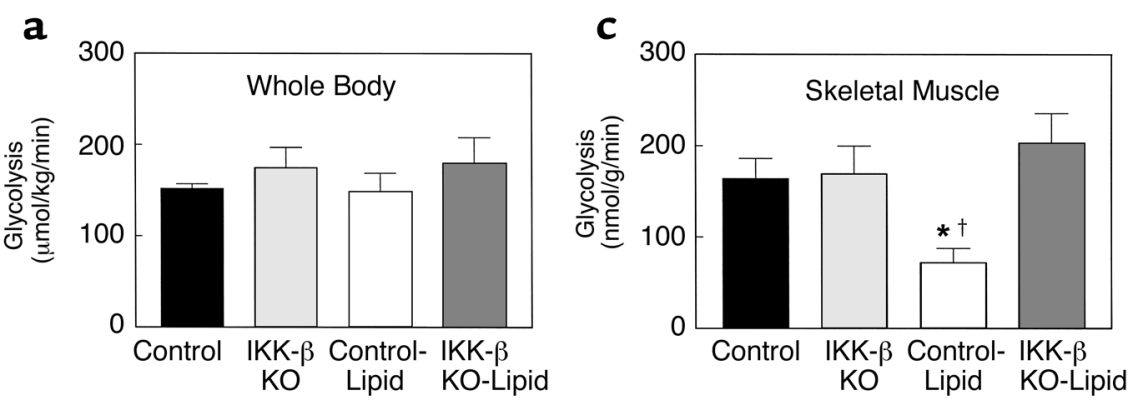

b

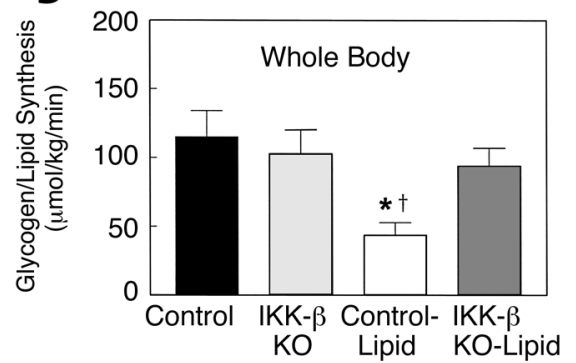

d

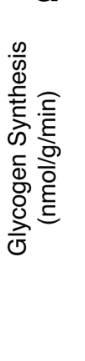

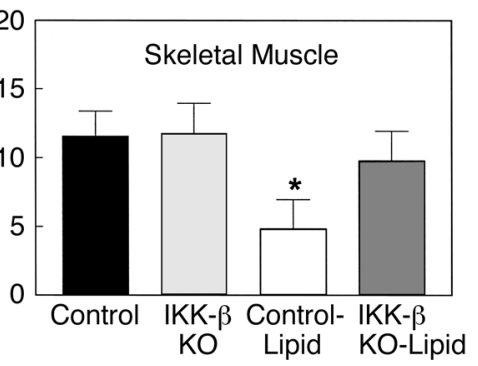

Figure 6

Insulin-stimulated whole-body and skeletal muscle (gastrocnemius) glucose metabolic flux in awake control (black bars), IKK- $\beta$ KO (light gray bars), control-lipid (open bars), and IKK- $\beta$ KO-lipid (dark gray bars) mice. (a) Insulin-stimulated whole-body glycolysis in vivo. (b) Insulin-stimulated whole-body glycogen/lipid synthesis in vivo. (c) Insulinstimulated skeletal muscle glycolysis in vivo. (d) Insulin-stimulated skeletal muscle glycogen synthesis in vivo. Values are means $\pm \mathrm{SE}$ for three to five experiments. ${ }^{*} P<0.05$ versus control group; ${ }^{\dagger} P<0.05$ versus IKK- $\beta$ KO-lipid group. 


\section{Figure 7}

Insulin signaling in skeletal muscle (gastrocnemius) and insulin action in fat of the control (black bars), IKK- $\beta$ KO (light gray bars), control-lipid (open bars), and IKK- $\beta$ KO-lipid (dark gray bars) mice. (a) Insulin-stimulated tyrosine phosphorylation of IRS-1 in skeletal muscle. (b) Insulin-stimulated IRS1-associated PI 3-kinase activity in skeletal muscle. (c) Insulin-stimulated glucose uptake in intrascapular brown adipose tissue. (d) Insulin-stimulated glucose uptake in epididymal white adipose tissue. Values are means $\pm \mathrm{SE}$ for three to five experiments. ${ }^{*} P<0.05$ versus control group; ${ }^{\dagger} P<0.05$ versus IKK- $\beta$ KO-lipid group.
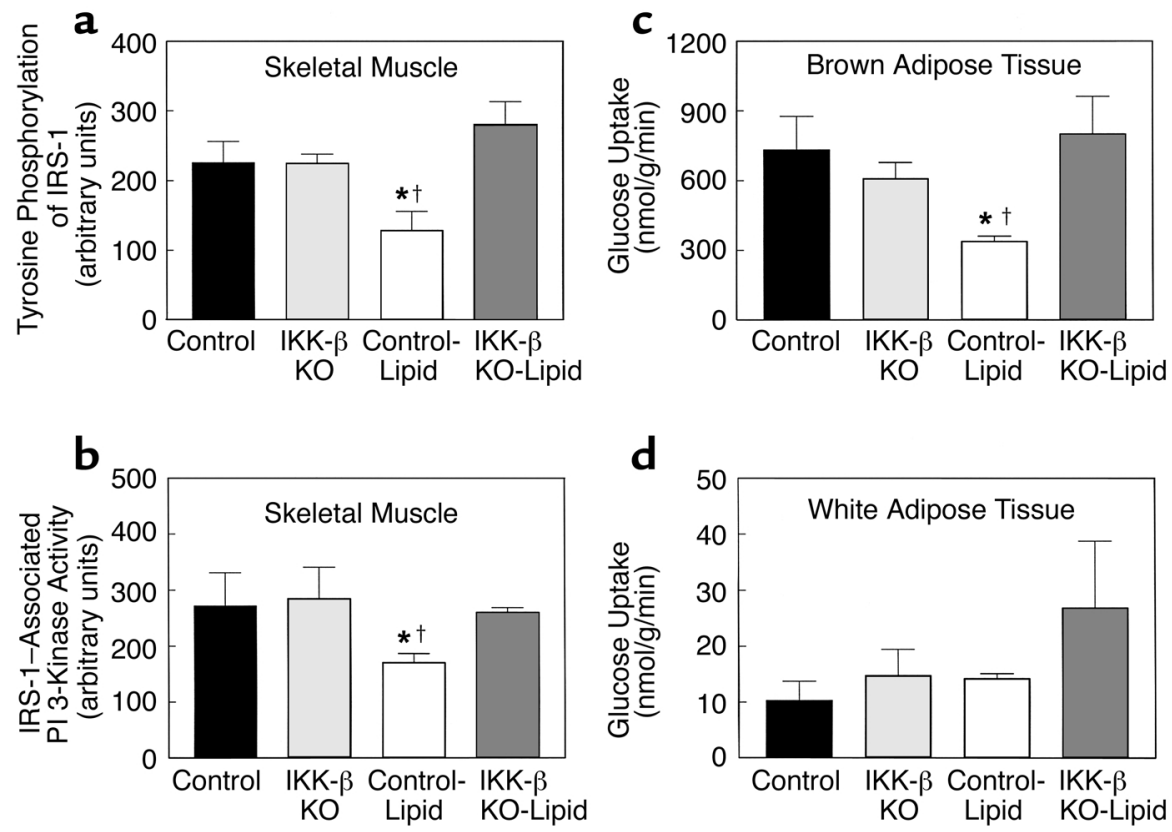

metabolism in rat skeletal muscle. Given that glucose transport is rate-controlling for glucose utilization in skeletal muscle $(20,21)$, decreases in glucose transport may account for the parallel decreases in glycolysis and glycogen synthesis with lipid infusion. These abnormalities were associated with defects in insulin activation of tyrosine phosphorylation of IRS-1 and IRS1-associated PI 3-kinase in skeletal muscle. Recent studies have shown that IRS-1-associated PI 3-kinase is an important intracellular mediator of insulin signaling in skeletal muscle (22), and insulin stimulation of both glucose transport and glycogen synthase activity has been associated with activation of IRS-1-associated PI 3-kinase in skeletal muscle (23). These findings suggest that defects in skeletal muscle insulin action may be secondary to the observed defects in skeletal muscle insulin signaling with lipid infusion. Interestingly, the decrease in insulin-stimulated muscle glycogen synthesis was more profound than the decrease in muscle glucose uptake. This may be due to additional downstream defects in insulin activation of PI 3-kinase that in turn affect insulin-stimulated glycogen synthase activity in skeletal muscle with lipid infusion. In contrast to the defects in insulin activation of tyrosine phosphorylation of IRS-1 and IRS-1-associated PI 3-kinase in skeletal muscle, insulin-stimulated tyrosine phosphorylation of the insulin receptor in the muscle was unaltered with lipid infusion. This finding suggests that the defect in insulin signaling with lipid infusion was not due to an alteration in plasma membrane or membrane-associated insulin receptors (24). It further suggests that the mechanism of blunted insulin signaling with lipid infusion occurs downstream of the insulin receptor and at the level of the IRS-1. Furthermore, a 5-hour lipid infusion did not alter insulin's ability to suppress EGP or stimulate glucose uptake in white adipose tissue.
The mechanism by which lipid infusion may affect muscle insulin signaling may involve increases in intracellular fatty acid derived metabolites (i.e., fatty acyl CoA, diacylglycerol, ceramides) and subsequent activation of a serine/threonine kinase (e.g., PKC- $\theta$, IKK- $\beta$ ). Chalkley et al. (25) have reported that a 5-hour lipid infusion increased muscle triglyceride and longchain fatty acyl CoA contents, and this increase in fatty acyl CoA might lead to an increase in diacylglycerol, a known potent activator of PKC- $\theta$ (26). Moreover, recent studies by our group have shown that an acute elevation of plasma fatty acids for 5 hours resulted in activation of PKC- $\theta$, which was associated with decreased tyrosine phosphorylation of IRS-1 (10). Mechanisms responsible for decreased insulin-stimulated tyrosine phosphorylation of IRS-1 may involve serine phosphorylation of IRS-1 (27-29), proteasomemediated degradation of IRS-1 $(30,31)$, or phosphatase-mediated dephosphorylation of IRS-1 (32, 33). In this regard, serine phosphorylation of IRS-1 impairs the ability of IRS- 1 to associate with the insulin receptor, which inhibits subsequent insulinstimulated tyrosine phosphorylation of IRS-1 $(10,24$, $34)$ and activation of IRS-1-associated PI 3-kinase (27, 28). Moreover, 5-hour lipid infusion did not alter IRS-1 protein content in rat skeletal muscle ( $222 \pm 21$ vs. 246 \pm 26 arbitrary units in controls). Thus, accumulation of diacylglycerol or fatty acyl CoA's due to lipid infusion (i.e., increased delivery of fatty acid into skeletal muscle) may be responsible for defects in insulin's ability to activate IRS-1-associated PI 3-kinase in skeletal muscle and subsequent insulin action. Furthermore, it is also possible that increased concentrations of other intracellular fatty acid derived metabolites, such as ceramide, may play a role in the lipid-induced insulin resistance in skeletal muscle. Summers and 
colleagues have shown that ceramide suppressed insulin-stimulated glucose transport in 3T3-L1 adipocytes by inhibiting phosphorylation and activation of Akt/protein kinase B, a serine/threonine protein kinase that is activated by insulin in a PI 3-kinase-dependent manner (35) and involved in the translocation of GLUT4 to the cell membrane (36).

The defects in skeletal muscle insulin signaling and action with lipid infusion were completely prevented with salicylate pretreatment, and the mechanism by which salicylate prevents insulin resistance may involve inhibition of IKK- $\beta$. Recently, Yin et al. (14) have shown that salicylate may prevent activation by NF- $\mathrm{KB}$ of genes involved in the pathogenesis of the inflammatory response by inhibiting the activity of IKK- $\beta$ and phosphorylation of IKB (at serines S32 and S36 in IKB $\alpha$ and S19 and S23 in IKB $\beta$ ). DiDonato et al. (37) and Zandi et al. (38) have recently shown that serine phosphorylation of I $\mathrm{KB}$ triggers ubiquitination and degradation of the I $\kappa \mathrm{B}$ and eventually activation of NF- $\kappa \mathrm{B}$, a transcription factor involved in immune and inflammatory response (39). Furthermore, TNF- $\alpha$, a wellknown proinflammatory cytokine, activates NF- $\kappa B$ by stimulating IKK activity (38), and salicylate has been demonstrated to inhibit TNF- $\alpha$-induced stimulation of IKK activity (14). Interestingly, TNF- $\alpha$ has also been shown to promote insulin resistance in adipocytes (40) and skeletal muscle (41) by decreasing insulin activation of IRS- 1 tyrosine phosphorylation (42) and IRS1-associated PI 3-kinase (43). From these findings, we hypothesized that lipid infusion may cause skeletal muscle insulin resistance by activating IKK- $\beta$, which subsequently leads to increased serine phosphorylation of IRS-1. Consistent with this hypothesis, we found that salicylate pretreatment prevented lipid-induced insulin resistance in skeletal muscle by possibly inhibiting the IKK- $\beta$ activity and preventing the lipid-induced decreases in tyrosine phosphorylation of IRS- 1 and IRS-1-associated PI 3-kinase activity.

To further examine the hypothesis that salicylate prevents lipid-induced insulin resistance in skeletal muscle by inhibiting IKK- $\beta$, we determined the effects of 5 -hour lipid infusion on skeletal muscle insulin signaling and action in mice with IKK- $\beta$ inactivation (16). A 5-hour lipid infusion significantly decreased insulin-stimulated glucose uptake and metabolic flux (i.e., glycogen synthesis, glycolysis) in skeletal muscle of the control mice. These lipid-induced defects in skeletal muscle insulin action were secondary to defects in muscle insulin signaling, as observed in rats. In contrast, lipid infusion failed to alter insulin-stimulated glucose uptake, tyrosine phosphorylation of IRS-1, and IRS-1-associated PI 3 -kinase activity in skeletal muscle of IKK- $\beta$ knockout mice. These findings implicate the protective role of IKK- $\beta$ inactivation on fat-induced development of skeletal muscle insulin resistance and further support the effects of salicylate on insulin action via inhibition of IKK- $\beta$ activity in skeletal muscle. However, we cannot rule out that salicylate may have additional roles on ribosomal S6 kinase 2 activity (44), kinase Erk activity (45), NF- $\kappa B$ activity $(37,44,45)$, or other potential targets of anti-inflammatory action (46) that in turn affect insulin action in skeletal muscle.

In summary, salicylate pretreatment prevents lipidinduced skeletal muscle insulin resistance by inhibiting lipid-induced decreases in insulin-stimulated IRS-1 tyrosine phosphorylation and IRS-1-associated PI 3-kinase activation. The effect of salicylate, a known inhibitor of IKK- $\beta$, on insulin action is further supported by our findings that mice with inactivation of IKK- $\beta$ are protected from lipid-induced skeletal muscle insulin resistance. Overall, these results provide important new insights into the mechanism of fat-induced insulin resistance in skeletal muscle and suggest a potentially novel class of therapeutic agents for type 2 diabetes.

\section{Acknowledgments}

This study was supported by grants from the United States Public Health Service: R01 DK-40936, P30 DK45735, and U24 DK-59635 (G.I. Schulman); and R01 DK-51729 and R01 DK-45493 (S.E. Shoelson). Jason K. Kim is a Research Associate, and Gerald I. Shulman is an Investigator of the Howard Hughes Medical Institute. We are grateful to Yan-Lin Wang, Jianying Dong, and Aida Groszmann for technical assistance.

1. DeFronzo, R.A. 1988. The triumvirate: beta-cell, muscle, liver. A collusion responsible for NIDDM. Diabetes. 37:667-687.

2. Reaven, G.M. 1988. Role of insulin resistance in human disease. Diabetes. 37:1595-1607.

3. Boden, G. 1997. Role of fatty acids in the pathogenesis of insulin resistance and NIDDM. Diabetes. 46:3-10.

4. Randle, P.J., Garland, P.B., Hales, C.N., and Newsholme, E.A. 1963. The glucose fatty acid cycle: its role in insulin sensitivity and the metabolic disturbances of diabetes mellitus. Lancet. 1:785-789.

5. Kelley, D.E., Mokan, M., Simoneau, J.-A., and Mandarino, L.J. 1993. Interaction between glucose and free fatty acid metabolism in human skeletal muscle. J. Clin. Invest. 92:91-98.

6. Zorzano, A., et al. 1985. Effects of starvation and exercise on concentrations of citrate, hexose phosphates, and glycogen in skeletal muscle and heart: evidence for selective operation of the glucose-fatty acid cycle. Biochem. J. 232:585-591.

7. Vaag, A., Handberg, A., Skott, P., Richter, E.A., and Beck-Nielsen, H. 1994. Glucose-fatty acid cycle operates in humans at the levels of both whole body and skeletal muscle during low and high physiological plasma insulin concentrations. Eur. J. Endocrinol. 130:70-79.

8. Roden, M., et al. 1996. Mechanism of free fatty acid-induced insulin resistance in humans. J. Clin. Invest. 97:2859-2865.

9. Dresner, A., et al. 1999. Effect of free fatty acids on IRS-1 associated PI 3-kinase activity. J. Clin. Invest. 103:253-259.

10. Griffin, M.E., et al. 1999. Free fatty acid-induced insulin resistance is associated with activation of protein kinase $\mathrm{C} \theta$ and alterations in the insulin signaling cascade. Diabetes. 48:1270-1274.

11. Le Marchand-Brustel, Y. 1999. Molecular mechanisms of insulin action in normal and insulin-resistant states. Exp. Clin. Endocrinol. Diabetes. 107:126-132.

12. Williamson, R.T., and Lond, M.D. 1901. On the treatment of glycosuria and diabetes mellitus with sodium salicylate. Brit. Med. J. 1:760-762.

13. Reid, J., MacDougall, A.I., and Andrews, M.M. 1957. Aspirin and diabetes mellitus. Brit. Med. J. 2:1071-1074.

14. Yin, M.-J., Yamamoto, Y., and Gaynor, R.B. 1998. The anti-inflammatory agents aspirin and salicylate inhibit the activity of IкB kinase- $\beta$. Nature. 396:77-80.

15. Kim, J.K., Wi, J.K., and Youn, J.H. 1996. Plasma free fatty acids decrease insulin-stimulated skeletal muscle glucose uptake by suppressing glycolysis in conscious rats. Diabetes. 45:446-453.

16. Yuan, M., et al. 2001. Reversal of obesity- and diet-induced insulin resistance with salicylates or targeted disruption of IKK $\beta$. Science. In press.

17. Kim, J.K., Gavrilova, O., Chen, Y., Reitman, M.L., and Shulman, G.I. 
2000. Mechanism of insulin resistance in A-ZIP/F-1 fatless mice. J. Biol. Chem. 275:8456-8460.

18. Storlien, L.H., et al. 1991. Influence of dietary fat composition on development of insulin resistance in rats. Relationship to muscle triglyceride and $\omega-3$ fatty acids in muscle phospholipid. Diabetes. 40:280-289.

19. Rossetti, L., and Giaccari, A. 1990. Relative contribution of glycogen synthesis and glycolysis to insulin-mediated glucose uptake. J. Clin. Invest. 85:1785-1792.

20. Cline, G.W., et al. 1999. Impaired glucose transport as a cause of decreased insulin-stimulated muscle glycogen synthesis in type 2 diabetes. N. Engl. J. Med. 341:240-246.

21. Ren, J.M., et al. 1993. Evidence from transgenic mice that glucose transport is rate-limiting for glycogen deposition and glycolysis in skeletal muscle. J. Biol. Chem. 268:16113-16115.

22. Yamauchi, T., et al. 1996. Insulin signaling and insulin actions in the muscles and livers of insulin-resistant, insulin receptor substrate 1-deficient mice. Mol. Cell. Biol. 16:3074-3084.

23. Kahn, C.R. 1994. Insulin action, diabetogenes, and the cause of type II diabetes. Diabetes. 43:1066-1084.

24. Watarai, T., et al. 1988. Alteration of insulin-receptor kinase activity by high fat feeding. Diabetes. 37:1397-1404.

25. Chalkley, S.M., Hettiarachchi, M., Chisholm, D.J., and Kraegen, E.W. 1998. Five-hour fatty acid elevation increases muscle lipids and impairs glycogen synthesis in the rat. Metabolism. 47:1121-1126.

26. Schmitz-Peiffer, C., et al. 1997. Alterations in the expression and cellular localization of protein kinase $\mathrm{C}$ isozymes epsilon and theta are associated with insulin resistance in skeletal muscle of the high-fat-fed rats. Diabetes. 46:169-178.

27. Hostamisligil, G.S. 1999. Mechanisms of TNF-alpha-induced insulin resistance. Exp. Clin. Endocrinol. Diabetes. 107:119-125.

28. Rui, L., et al. 2001. Insulin/IGF-1 and TNF- $\alpha$ stimulate phosphorylation of IRS-1 at inhibitory $\mathrm{Ser}^{307}$ via distinct pathways. J. Clin. Invest. 107:181-189.

29. Hostamisligil, G.S., et al. 1996. IRS-1 mediated inhibition of insulin receptor tyrosine kinase activity in TNF- $\alpha$ - and obesity-induced insulin resistance. Science. 271:665-668.

30. Stephens, J.M., Lee, J., and Pilch, P.F. 1997. Tumor necrosis factor- $\alpha$ induced insulin resistance in 3T3-L1 adipocytes is accompanied by a loss of insulin receptor substrate-1 and GLUT4 expression without a loss of insulin receptor-mediated signal transduction. J. Biol. Chem. 272:971-976.

31. Egawa, K., et al. 2000. Persistent activation of phosphatidylinositol 3kinase causes insulin resistance due to accelerated insulin-induced insulin receptor substrate-1 degradation in 3T3-L1 adipocytes. Endocrinology. 141:1930-1935.

32. Elchebly, M., et al. 1999. Increased insulin sensitivity and obesity resistance in mice lacking the protein tyrosine phosphatase-1B gene.
Science 283:1544-1548

33. Goldstein, B.J., Ahmad, F., Ding, W., Li, P.M., and Zhang, W.R. 1998. Regulation of the insulin signaling pathway by cellular protein-tyrosine phosphatases. Mol. Cell. Biochem. 182:91-99.

34. Paz, K., et al. 1997. A molecular basis for insulin resistance. Elevated serine/threonine phosphorylation of IRS-1 and IRS- 2 inhibits their binding to the juxtamembrane region of the insulin receptor and impairs their ability to undergo insulin-induced tyrosine phosphorylation. J. Biol. Chem. 272:29911-29918.

35. Summer, S.A., Garza, L.A., Zhou, H., and Birnbaum, M.J. 1998. Regulation of insulin-stimulated glucose transporter GLUT4 translocation and Akt kinase activity by ceramide. Mol. Cell. Biol. 18:5457-5464.

36. Calera, M.R., et al. 1998. Insulin increases the association of Akt-2 with Glut4-containing vesicles. J. Biol. Chem. 273:7201-7204.

37. DiDonato, J.A., Hayakawa, M., Rothward, D.M., Zandi, E., and Karin, M. 1997. A cytokine-responsive IKB kinase that activates the transcription factor NF- $\kappa$ B. Nature. 388:548-554.

38. Zandi, E., Rothward, D.M., Delhase, M., Hayakawa, M., and Karin, M. 1997. The IкB kinase complex (IKK) contains two kinase subunits, IKKo and IKK $\beta$, necessary for IKB phosphorylation and NF- $\mathrm{KB}$ activation. Cell. 91:243-252.

39. Barnes, P.J., and Karin, M. 1997. Nuclear factor-КB-A pivotal transcription factor in chronic inflammatory diseases. N. Engl. J. Med. 336:1066-1071.

40. Liu, L.S., Spelleken, M., Rohrig, K., Hauner, H., and Eckel, J. 1998. Tumor necrosis factor- $\alpha$ acutely inhibits insulin signaling in human adipocytes Diabetes. 47:515-522.

41. Hotamisligil, G.S., and Spiegelman, B.M. 1994. Tumor necrosis factor $\alpha$ a key component of the obesity-diabetes link. Diabetes. 43:1271-1278.

42. Kanety, H., Hemi, R., Papa, M.Z., and Karasik, A. 1996. Sphingomyelinase and ceramide suppress insulin-induced tyrosine phosphorylation of the insulin receptor substrate-1. J. Biol. Chem. 271:9895-9897.

43. Guo, D., and Donner, D.B. 1996. Tumor necrosis factor promotes phosphorylation and binding of insulin receptor substrate-1 to phosphatidylinositol 3-kinase in 3T3-L1 adipocytes. J. Biol. Chem. 271:615-618.

44. Stevenson, M.A., Zhao, M.J., Asea, A., Coleman, C.N., and Calderwood, S.K. 1999. Salicylic acid and aspirin inhibit the activity of RSK2 kinase and repress RSK2-dependent transcription of cyclic AMP response element binding protein- and NF-kappa B-responsive genes. J. Immunol. 163:5608-5616

45. Pilinger, M.H., et al. 1998. Modes of action of aspirin-like drugs: salicylates inhibit erk activation and integrin-dependent neutrophil adhesion. Proc. Natl. Acad. Sci. USA. 95:14540-14545.

46. Alpert, D , and Vilek, J. 2000. Inhibition of IкB kinase activity by sodium salicylate in vitro does not reflect its inhibitory mechanism in intact cells. J. Biol. Chem. 275:10925-10929. 